\title{
Crystal Engineering for Pharmaceutical Solids
}

\section{Partha Pratim Bag*}

Department of Basic Science and Humanities (Chemistry), Dumka Engineering College, Dumka, Jharkhand, India

*Corresponding Author: Partha Pratim Bag, Department of Basic Science and Humanities (Chemistry), Dumka Engineering College, Dumka, Jharkhand, India.
Received: February 04, 2020

Published: February 18, 2020

(C) All rights are reserved by Partha Pratim

Bag.
Pharmaceutical companies are extensively dedicated to conduct research for the development of the solubility of limited aqueous soluble drug molecules and their bioavailability. Less soluble molecule can provide a number of challenges in pharmaceutical development such as slow dissolution in biological fluids, insufficient and inconsistent systemic exposure and consequent sub-optimal efficacy in patients via the oral route of administration [1]. Continuously an intensive research in the pharmaceutical sciences has documented several approaches to address the issues of low aqueous solubility and bioavailability.

Solid drug substances demonstrate spacious and mostly unpredictable variable properties of solid state. Among different types of solids active pharmaceutical ingredients (APIs) represent a classical challenge to crystal engineers due to both fundamental and applied reasons. The structure of an API is core factor of its property, as inherent structural change can modify its unique property. However, the crystal packing of APIs are less predictable than that of other organics because of their flexible possibility for self-assembly which reveals the concept of "polymorphism" [2]. During self assembly of API's solvent molecules may present in their crystal structure which originates the term "solvate" or "hydrate" (in case of water). Again more than one API or generally regarded as safe (GRAS) material can be assemble in their own way which produces the idea of "co-crystal" or "co-crystal polymorph". In this view point the importance of an crystal engineers is very crucial and it define "the understanding of intermolecular interactions in the context of crystal packing and in the utilization of such understanding in the design of new solids with desired physical and chemical properties" [3]. By designing the solid pharmaceutical materials using Crystal Engineering approach and finding their structures may find some fruitful solution to those low soluble drug molecules. Nowa-days such issues are of highly acceptable in academic section as intellectual property implications are considerable and physical properties and bioavailability are often critically dependent upon crystal packing [4]. This is the novelty of Crystal Engineering.

Among different solid forms, co-crystals are highly accepted forms in pharmaceutical industry. By forming co-crystal of an API, the physicochemical properties can be modified without changing its original activity. The change of physicochemical properties of an API is highly advantageous to the pharmaceutical community. As for example, some API having solubility problem will be overcome without changing its activity [5] or tabletability property will be enhanced by co-crystallization [6]. So a suitable design of co- crystals/solid forms using the idea of Crystal Engineering might be a crucial technique to overcome the existing problem.

\section{Bibliography}

1. Blagden N., et al. "Crystal engineering of active pharmaceutical ingredients to improve solubility and dissolution rates". Advanced Drug Delivery Reviews 59 (2007): 617-630.

2. Desiraju GR. "Crystal Gazing: Structure Prediction and Polymorphism”. Science 278 (1997): 404-405.

3. Desiraju GR. "Crystal Engineering: The design of Organic Solids". Elsevier, Amsterdam (1989).

4. Seddon KR and Zaworotko MJ. "Crystal Engineering: The Design and Application of Functional Solids". NATO-ASI Series. Kluwer: Dordrecht, The Netherlands 539 (1999).

5. Black SN., et al. "Structure, solubility, screening and synthesis of molecular salts". Journal of Pharmaceutical Sciences 96 (2007): 1053-1068.

6. Dai XL., et al. "Pharmaceutical cocrystallization: an effective approach to modulate the physicochemical properties of solid-state drugs". CrystEngComm 20 (2018): 5292-5316.

\section{Assets from publication with us}

- Prompt Acknowledgement after receiving the article

- Thorough Double blinded peer review

- Rapid Publication

- Issue of Publication Certificate

- High visibility of your Published work

Website: www.actascientific.com/

Submit Article: www.actascientific.com/submission.php

Email us: editor@actascientific.com

Contact us: +919182824667 